Check for updates

Cite this: RSC Adv., 2019, 9, 30453

\title{
A novel forced separation method for the preparation of paraffin with excellent phase changes
}

\begin{abstract}
Gang Bai, ${ }^{a}$ Qinzhen Fan, ${ }^{* b}$ Jianfeng Sun, ${ }^{c}$ Lihua Cheng ${ }^{b}$ and Xi-Ming Song (DD *a
A novel forced separation method based on driving force vacuum sweating was used to prepare high melting point paraffin with high phase-change enthalpies. The effects of the vacuum pressure and final separation temperature on the forced separation of the paraffin components were investigated. The research results showed that the optimal vacuum pressure for forced separation was $80.0 \mathrm{kPa}$. The performance of forced separation was improved with the increase in the final temperature. Increasing the final temperature increased the driving force of the separation of solid-state components and liquid components during sweating, which improved the product yield, shortened the production cycle, and reduced the oil content. The phase changes exhibited by the separation products were tested at $70{ }^{\circ} \mathrm{C}$ under optimal conditions. The raw materials and forced separation products were analyzed through Fourier transform infrared spectroscopy analysis (FT-IR), gas chromatography analysis (GC), differential scanning calorimetry analysis (DSC), and X-ray diffraction analysis (XRD). The results of these analyses showed that as the forced separation temperature was increased, the carbon atom number distribution range of the products narrowed, and the content of $n$-paraffin was drastically improved. The content of $n$-paraffin in the final fraction obtained through the forced separation of paraffin was $89.8 \%$ with a phase-transition temperature of $69.74{ }^{\circ} \mathrm{C}$ and a phase-transition enthalpy of $214.71 \mathrm{~J} \mathrm{~g}^{-1}$. A significant solid-solid phase transition peak was observed in the final fraction obtained through the forced separation of paraffin, which verified that paraffin was an excellent phase-change material for energy storage.
\end{abstract}

Received 24th June 2019

Accepted 21st August 2019

DOI: $10.1039 / c 9 r a 04722 k$

rsc.li/rsc-advances temperature. ${ }^{1,2}$ Therefore, it is widely used in solar thermal utilization, industrial waste heating, clothing, and construction..$^{3-9}$ Seitz et al.,$^{10}$ for example, recently reported a novel PCM with the use of PAA and PAH as electrostatically interacting shell materials for energy storage applications, which could be expanded for use with various paraffin-type PCMs.

However, there were many problems with the reported paraffin products, including a wide carbon atom distribution and low $n$-paraffin composition. Therefore, paraffin had difficulty in satisfying the demands of phase-change materials due to its high enthalpy during the solid-liquid phase transition, which limited its applications in thermal energy storage and industry applications.

The main methods used for paraffin production include molecular sieve dewaxing, ${ }^{11}$ urea dewaxing, ${ }^{12}$ molecular distillation,,$^{13}$ the solvent method, ${ }^{14}$ and sweating. ${ }^{15,16}$ Molecular sieve dewaxing and urea dewaxing are unsuitable for the production of PCMs with high melting points. Distillation, which involves separating different hydrocarbon substances in accordance with their different boiling points, requires a high number of tower plates for precise separation with increased pressure drops. Distillation is unsuitable for the production of paraffin due to the hydrocarbons forming solid paraffins and an oily 
fraction with higher average molecular weight petroleum distillates.

The solvent method, which separates normal paraffin and other hydrocarbon substances on the basis of their different solubilities in certain solvents, is unsuitable for the production of paraffin with high enthalpy performance because it has a negligible effect on narrowing the range of the carbon atom number distribution. The sweating method, which separates and purifies the various components in the raw materials on the basis of their different melting points, is a technically simple and environmentally friendly process that can be conducted without the addition of a solvent. It is significantly affected by the molecular weights and structures at the melting points of paraffin, which increase with the molecular weight. However, for the same molecular weight, the melting point of $n$-paraffin is higher than that of the branched paraffin associated with low melting points. Therefore, the sweating method could simultaneously enrich the $n$-paraffin content and narrow the range of the carbon atom number distribution, which makes it suitable for the production of PCMs. However, due to the higher content of branched alkanes in the waxes with high melting points and higher viscosity, a microcrystalline crystallization behavior is exhibited in the sweating method, which hampers the separation of the oil from the solid.

This study aimed to resolve the difficulties encountered in the complete separation of $n$-paraffin with high melting points from liquid oil with low melting points in conventional sweating. In this paper, a novel method of forced separation was studied to overcome the disadvantages of the low product yield and long operation period in the process of conventional sweating for the preparation of excellent phase-change paraffin. In this new method, the driving force of separation was increased by the formation of negative pressure, which improved the separation rate, enhanced the separation efficiency, and shortened the production cycle. The research results could provide both a practical foundation and theoretical support for the production of phase-change paraffin with high melting points, which could also be applied in related fields.

\section{Experimental section}

\subsection{Materials and instruments}

2.1.1 Raw material (1). The melting point and oil content of slack wax from Daqing (located in Northeast of China) crude oil with the distillated fraction from $370{ }^{\circ} \mathrm{C}$ to $450{ }^{\circ} \mathrm{C}$ were $51.2{ }^{\circ} \mathrm{C}$ and $17.8 \%$, respectively. The results from the simulated distillation are shown in Table 1.

2.1.2 Raw material (2). Paraffin wax (melting point $64.3^{\circ} \mathrm{C}$ ) was fabricated by PetroChina Fushun Petrochemical Company. The properties of the paraffin are shown in Table 2.

Table 1 Results of the simulated distillation of slack wax

\begin{tabular}{lllllll}
\hline IBP & $10 \%$ & $30 \%$ & $50 \%$ & $70 \%$ & $90 \%$ & $95 \%$ \\
\hline $246{ }^{\circ} \mathrm{C}$ & $394{ }^{\circ} \mathrm{C}$ & $407{ }^{\circ} \mathrm{C}$ & $416{ }^{\circ} \mathrm{C}$ & $422{ }^{\circ} \mathrm{C}$ & $434{ }^{\circ} \mathrm{C}$ & $451{ }^{\circ} \mathrm{C}$
\end{tabular}

\subsection{Instruments and equipment}

The paraffin decompression and sweating forced separation device is illustrated in Fig. 1.

\subsection{Basic theory of the sweating process}

Sweating is the separation of hydrocarbon substances with different melting points. It mainly involves two steps: cold oil processing and sweating. The molten raw material is cooled slowly during cold oil processing. Various components undergo successive crystallization on the basis of their melting points, from high to low, and form a fibrous structure with numerous voids that are filled with liquid components. During sweating, the liquid components gradually leach out of the paraffin crystal voids as the temperature is increased, and a PCM with a high melting point is obtained in the form of a wax layer residue as the final product.

In this work, gravity was ignored, and the liquid was set to flow in a vertical tube with a tube radius of $R$ and height of $h$ during sweating. The upper pressure was $P_{1}$, the lower pressure was $P_{2}$, and $P_{1}>P_{2}$, as shown in Fig. 2 .

A cylindrical fluid with a tube coaxial radius of $R$ was taken to calculate the pressure difference $(\Delta F)$ and the friction $(f)$ from the following equations:

$$
\begin{array}{r}
\Delta F=\left(P_{1}-P_{2}\right) \pi r^{2} \\
f=-2 \eta \pi r h \frac{\mathrm{d} v}{\mathrm{~d} r}
\end{array}
$$

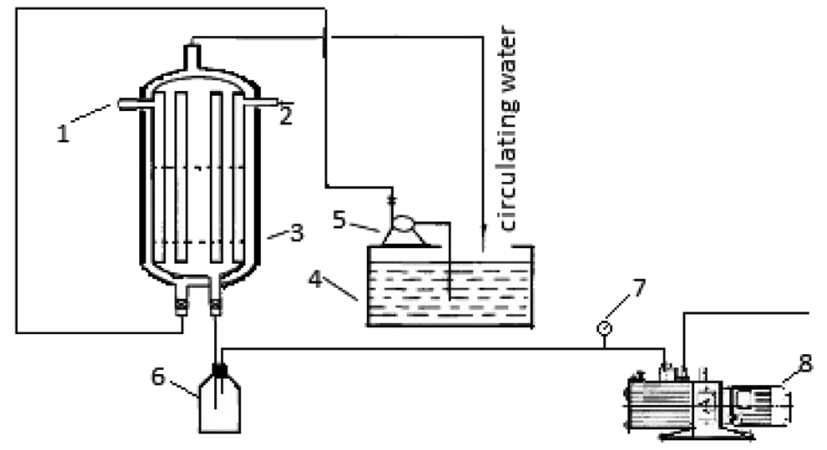

Fig. 1 Schematic of forced separation through the vacuum sweating method. 1 - Blow vent, 2 - feed inlet, 3 - sweating tank, 4 - constant temperature water bath, 5 - pump, 6 - glass jar for product, 7 vacuum pressure gauge, 8 - aspirator vacuum pump. 


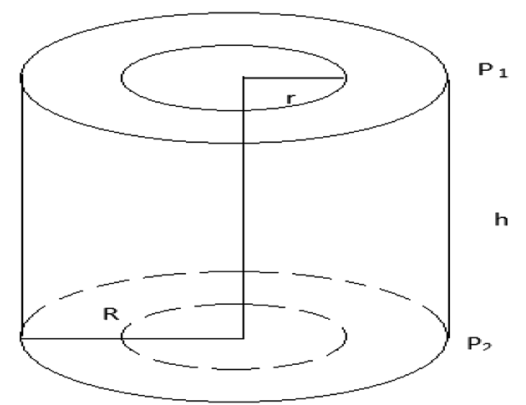

Fig. 2 Schematic of the vacuumed sweating model.

As the two forces were equal in a stable fluid, the following equation is obtained:

$$
\left(P_{1}-P_{2}\right) \pi r^{2}=-2 \eta \pi r h \frac{\mathrm{d} v}{\mathrm{~d} r}
$$

therefore,

$$
\mathrm{d} v=-\frac{P_{1}-P_{2}}{2 \eta h} r \mathrm{~d} r
$$

Given that $r=R, v=0$, the flow rate was $v$ when the radius was $r$, and we can get the following equation through the integration of both sides:

$$
v=\frac{P_{1}-P_{2}}{4 \eta h}\left(R^{2}-r^{2}\right)
$$

A tubular flow layer with a radius of $r$ and a thickness of $\mathrm{d} r$ was taken for analysis, and the cross-sectional area of the flow layer was $\mathrm{d} S=2 \pi r \mathrm{~d} r$, therefore we could get the following equation:

$$
\mathrm{d} Q=v \mathrm{~d} S=\pi \frac{P_{1}-P_{2}}{2 \eta h}\left(R^{2}-r^{2}\right) r \mathrm{~d} r
$$

The general flow eqn (6) can be expressed as:

$$
Q=\frac{\pi R^{4}\left(P_{1}-P_{2}\right)}{8 \eta h}
$$

Only considering the effect of gravity, the equation of the pressure difference could be rewritten as:

$$
\Delta F=m g=\pi r^{2} \rho g h
$$

As $\Delta F=f$, the following equation is obtained:

$$
\pi r^{2} \rho g h=-2 \eta \pi r h \frac{\mathrm{d} v}{\mathrm{~d} r}
$$

therefore,

$$
\mathrm{d} v=-\frac{\pi r^{2} \rho g h \mathrm{~d} r}{2 \eta \pi r h}=-\frac{\rho g}{2 \eta} r \mathrm{~d} r
$$

Through integration, eqn (10) can be rewritten as:

$$
v=\frac{\rho g}{2 \eta}\left(\frac{1}{2} R^{2}-\frac{1}{2} r^{2}\right)=\frac{\rho g}{4 \eta}\left(R^{2}-r^{2}\right)
$$

as

$$
\mathrm{d} S=2 \pi r \mathrm{~d} r
$$

therefore,

$$
\mathrm{d} Q=v \mathrm{~d} S=\frac{\rho g}{4 \eta}\left(R^{2}-r^{2}\right) 2 \pi r \mathrm{~d} r
$$

The performance of the volume of paraffin is calculated by the following equation:

$$
Q=\frac{\pi \rho g}{2 \eta}\left[R^{2} \frac{1}{2} r^{2}-\frac{1}{4} r^{4}\right]_{0}^{R}=\frac{\pi \rho g R^{4}}{8 \eta}
$$

The equation for the volume of paraffin that flows out per unit time during the vacuum sweating is obtained by simultaneously integrating eqn (7) and (14)

$$
Q=\frac{\pi R^{4}\left(P_{1}-P_{2}\right)}{8 \eta h}+\frac{\pi \rho g R^{4}}{8 \eta}=\frac{\pi R^{4}}{8 \eta h}(\Delta P+\rho g h)
$$

here, $R$ in sweating was determined in cold oil processing. Then, $\frac{\pi R^{4}}{8 \eta h}$ can be considered as a fixed value.

The separating efficiency (SE) is defined as the following:

$$
\mathrm{SE}=\frac{C_{\mathrm{oil}}-C_{f-\mathrm{oil}}}{C_{\mathrm{oil}}} \times 100 \%
$$

where $C_{\text {oil }}$ is the oil content of the feedstock, and $C_{f-\text { oil }}$ is the oil content of the fraction.

Eqn (15) shows that $\Delta P$ can be easily adjusted during vacuum sweating, and large $\Delta P$ values reflect that high volumes of liquid flow out per unit time. In conventional sweating, $P_{1}=P_{2}$, that is, $\Delta P=0$. The formation of negative pressure in the lower part of the paraffin layer during sweating can increase $\Delta P$, that is, increasing the driving force of the flow out of the liquid component during vacuum sweating improves the efficiency and the effect of the sweating (Fig. 3).

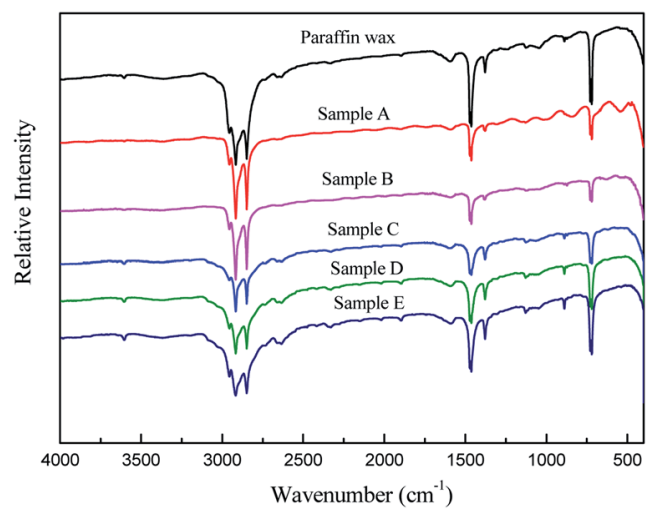

Fig. 3 Infrared spectra of the fractions obtained through the forced separation of paraffin. 


\subsection{Experimental process}

The conventional sweating process mainly consists of the following steps:

(1) The lower space of the dish plate of sweat device is filled with water. (2) Liquid raw material is then loaded into the sweating device after being heated to the melting point. (3) The raw material is cooled to a pre-set temperature at a rate of $4.0 \pm 0.5{ }^{\circ} \mathrm{C} \mathrm{h}^{-1}$. (4) The insulating water is released. The raw material is heated to the pre-set sweating final temperature at a warming rate of $1.0 \pm 0.5^{\circ} \mathrm{C}$ $\mathrm{h}^{-1}$. (5) The product is collected by continuously increasing the temperature to melt and remove the wax product. The vacuum system is activated during sweating, and the vacuum pressure is maintained in the buffer bottle to form a pressure difference up and down the paraffin layer during the forced separation sweating process.

\subsection{Sample preparation}

The raw materials or the forced separation products were mixed with copper powder ( 800 mesh) at a mass ratio of $1: 3$ and evenly loaded into the stroke test apparatus. The stroke test apparatus was first put into the constant temperature water bath with the temperature $10 \pm 0.1^{\circ} \mathrm{C}$ lower than the melting point of the sample to be measured, which was marked as $0 \%$ after the distance of stroke $L_{1}$ was stable. Second, the constant temperature water bath was increased to a temperature $10{ }^{\circ} \mathrm{C}$ higher than the melting point of the sample to be measured at a heating rate of $1.0 \pm$ $0.1{ }^{\circ} \mathrm{C} \mathrm{min}^{-1}$, and then testing was stopped, and recorded as $100 \%$ for the distance of stroke $L_{2}$. The length of the stroke $L$, which corresponded to each test temperature point, was converted into the relative stroke $(L \%)$, and the difference in the relative stroke between $L_{i} \%$ of a certain temperature and $L_{i-1} \%$ of the previous temperature was recorded as the relative travel difference $\Delta L \%$.

\subsection{Sample characterization}

Structural analysis of the composites materials was carried out on a Nicolet 6700 FT-IR spectrometer. The phase-change temperature and latent heat of the composite materials were obtained using a differential scanning calorimeter (DSC-60, Shimadzu). The DSC test temperature ranged from $20{ }^{\circ} \mathrm{C}$ to $100{ }^{\circ} \mathrm{C}$ and the rate of heating was $10^{\circ} \mathrm{C} \min ^{-1}$. The X-ray diffraction (XRD) pattern was recorded on a PANalytical X'Pert PRO with a step of $0.02^{\circ}$ using $\mathrm{Cu} \mathrm{K} \alpha$ radiation $(\lambda=1.5418 \AA)$. The paraffin composition was determined through gas chromatography (GC) using an Agilent 6890 PLUS gas chromatograph and iso-octane as a solvent at the initial column temperature of $120{ }^{\circ} \mathrm{C}$, heating rate of $3{ }^{\circ} \mathrm{C} \mathrm{min}{ }^{-1}$, and vaporization temperature of $375^{\circ} \mathrm{C}$. C14-C40 normal paraffin was used as the standard sample. The paraffin melting point was determined on the basis of ASTM D87-09 (2018). The paraffin oil content was determined in accordance with ASTM D721-2017.

\section{Results and discussion}

\subsection{Experimental}

3.1.1 Examination of forced separation conditions. The properties of the raw material slack wax from Daqing crude oil with the distillated fraction from $370{ }^{\circ} \mathrm{C}$ to $450{ }^{\circ} \mathrm{C}$ are shown in Table 1 . This material was used to investigate the influence of the vacuum pressure and final sweating temperature on the effectiveness of the forced separation.

3.1.1.1 Effect of vacuum pressure. The comparative analysis of the performances of conventional sweating and vacuum sweating under different vacuum pressures was carried out from the starting temperature of $40{ }^{\circ} \mathrm{C}$ to a final temperature of $46{ }^{\circ} \mathrm{C}$ with a heating rate of $1{ }^{\circ} \mathrm{C} \mathrm{h}^{-1}$. The results are shown in Table 3.

As shown in Table 3, the vacuum pressure had little influence on the melting point of wax, but it could significantly reduce the oil content, which decreased with the increase in the vacuum degree. The maximum yield was obtained under a vacuum pressure of $80.0 \mathrm{kPa}$, but the yield decreased as the vacuum pressure further increased; this phenomenon could be explained by the fact that cracks were produced on the uneven wax layer by the excessive vacuum, which led to a lower product yield and higher melting point in the product due to the excessive local gas flow rate. Therefore, the vacuum pressure of $80.0 \mathrm{kPa}$ was considered optimal in this experiment.

3.1.1.2 Effect of final temperature on forced separation. The performances of conventional sweating and forced separation sweating were compared under the vacuum pressure of $80.0 \mathrm{kPa}$ with an initial sweating temperature of $40{ }^{\circ} \mathrm{C}$ at a heating rate of $1{ }^{\circ} \mathrm{C} \mathrm{h}^{-1}$. The results are shown in Table 4 .

As shown in Table 4, the oil content and the yield of the separated fractions decreased with the finial sweating temperatures for both conventional sweating and forced separation sweating, whereas the melting point increased with the temperature. Of particular concern was the wax oil content observed in experiment $\mathrm{X}$ for vacuum sweating, which decreased to less than $1 \%$, whereas that observed in experiment XII significantly decreased to $0.53 \%$. However, the wax oil content observed in experiment XI for conventional sweating remained high at $2.75 \%$ at the same final sweating temperature as experiment XII. Therefore, it was beneficial to increase the final sweating temperature for the separation of the paraffin fractions.

The comparative analysis of conventional sweating and forced separation sweating under different vacuum pressures and at different final sweating temperatures revealed that the vacuum sweating improved the yield, shortened the production cycle, and reduced the oil content, which could give a beneficial improvement for ordinary sweating. Compared with the

Table 3 Comparative analysis of conventional sweating and vacuum sweating

\begin{tabular}{llrrrrr}
\hline Item & I & II & III & IV & V & \multicolumn{1}{c}{ VI } \\
\hline Vacuum degree, kPa & $0^{a}$ & 40.0 & 53.3 & 66.7 & 80.0 & 93.3 \\
Yield, \% & 48.9 & 49.4 & 51.0 & 51.6 & 52.6 & 49.5 \\
Oil content, \% & 6.5 & 3.3 & 3.3 & 3.25 & 2.75 & 2.1 \\
Melting point, ${ }^{\circ} \mathrm{C}$ & 53.8 & 54.0 & 54.0 & 53.9 & 53.9 & 54.3 \\
${ }^{a}$ Conventional sweating. & & & & &
\end{tabular}


Table 4 Comparison of the performances of vacuum sweating and conventional sweating at different final temperatures ${ }^{a}$

\begin{tabular}{lllllllll}
\hline Item & $\mathrm{I}$ & $\mathrm{V}$ & $\mathrm{VII}$ & $\mathrm{VIII}$ & $\mathrm{IX}$ & $\mathrm{X}$ & $\mathrm{XI}$ & $\mathrm{XII}$ \\
\hline$T_{\text {-start }} /{ }^{\circ} \mathrm{C}$ & 40 & 40 & 40 & 40 & 40 & 40 & 40 & 40 \\
$T_{\text {-end }}{ }^{\circ} \mathrm{C}$ & 46 & 46 & 48 & 48 & 50 & 50 & 52 & 52 \\
Vacuum degree $/ \mathrm{kPa}$ & $0^{b}$ & 80.0 & $0^{b}$ & 80.0 & $0^{b}$ & 80.0 & $0^{b}$ & 80.0 \\
Yield $/ \%$ & 48.9 & 52.6 & 45.3 & 48.3 & 42.8 & 46.0 & 39.9 & 42.4 \\
Oil content $/ \%$ & 6.5 & 2.75 & 4.05 & 1.49 & 3.90 & 0.95 & 2.75 & 0.53 \\
Melting point $/{ }^{\circ} \mathrm{C}$ & 53.8 & 53.9 & 54.6 & 54.5 & 54.6 & 54.8 & 55.2 & 55.2
\end{tabular}

${ }^{a} T_{\text {-start }}$ and $T_{\text {-end }}$ are the start and end of the sweating temperatures, respectively. ${ }^{b}$ Conventional sweating.

conventional sweating, the driving force of the separation of solid-state components from liquid components could be increased by more than 30 times during the early stage of the vacuum sweating, and even by hundreds of times in the final stages with the vacuum pressure of $80.0 \mathrm{kPa}$ and wax layer height of $30 \mathrm{~cm}$. The forced separation method, through the improvement of conventional sweating, could discharge a large amount of oil as soon as possible in the early stage of sweating, which greatly reduced the amount of wax components dissolved in the oil, leading to the yield of vacuum sweating being higher than in conventional sweating. As shown in Table 4, compared with the conventional sweating method, the yield of the product through vacuum sweating at $80 \mathrm{kPa}$ increased by $12.7 \%$ from $39.9 \%$ to $52.6 \%$ at the same production specification of $2.75 \%$ oil content for the slack wax from Daqing crude oil; whereas the final temperature of the reaction was reduced by $6{ }^{\circ} \mathrm{C}$, and the reaction time was reduced by $50 \%$. In the later period of sweating, it was difficult for the conventional sweating to discharge the small amount of oil adsorbed on the wax crystallization surface only through the action of gravity. However, vacuum sweating could improve the separation by forcing air through the wax layer to entrap the residual oil, thus effectively improving the separation effect.

3.1.2 Preparation of PCMs with high melting points. The raw materials (2) were used to prepare PCMs with high melting points under the conditions determined through the above tests. The temperature ranges of the different graded outflow products are shown in Table 5.

Based on the previous experiments, the optimal conditions were as follows: vacuum pressure of $80.0 \mathrm{kPa}$, sweating starting temperature of $60.0^{\circ} \mathrm{C}$, and heating rate of $1{ }^{\circ} \mathrm{C} \mathrm{h}^{-1}$. Tests on forced sweating separation were performed under the conditions shown in Table 5. The results are shown in Table 6.

As was known, the paraffin waxes of petroleum were crystalline below their melting point, with the size of the crystals decreasing with the increasing boiling point, which led to more oil being retained in the paraffin wax with high melting point. As is shown in Table 6, the melting point of the forced separation fraction increased significantly from $64.3^{\circ} \mathrm{C}$ to $69.3^{\circ} \mathrm{C}$ with the increase in the final separation temperature, while the oil content dramatically decreased from $0.46 \%$ to $0.07 \%$ with the separation efficiency improving to $84.78 \%$. However, this was unsuitable for the production of wax products with melting points of approximately $70{ }^{\circ} \mathrm{C}$ through the conventional sweating method, which could separate the soap wax and paraffin with low melting points of $40{ }^{\circ} \mathrm{C}$ to $60{ }^{\circ} \mathrm{C}$. The solid components (wax with a high melting point) and liquid components (wax with oil and low melting points) were difficult to completely separate through the conventional sweating process despite them being in different phases. It could be inferred from this that the range of carbon atom distribution and the content of normal paraffin in the final wax component during the late stage of conventional sweating were independent of the yield of wax products with melting points of approximately $70{ }^{\circ} \mathrm{C}$.

3.1.3 Analysis of the properties of the forced separation products

3.1.3.1 Infrared spectral analysis of the products. The absence of absorption peaks above $3000 \mathrm{~cm}^{-1}$ and within the range of $1500-2800 \mathrm{~cm}^{-1}$ in the infrared spectra of the raw materials (2) and forced separation fractions indicated that they were hydrocarbon substances without unsaturated bonds and carbon heterocyclic bonds, which also proved that there were no chemical reactions occurring during the forced separation process. The absorption peaks at $2916 \mathrm{~cm}^{-1}$ and $2848 \mathrm{~cm}^{-1}$ were ascribed to the alkyl stretching vibrations of $-\mathrm{CH}_{2}$ and $-\mathrm{CH}_{3}$, respectively. The absorption peaks at $1466 \mathrm{~cm}^{-1}$ and $1378 \mathrm{~cm}^{-1}$ were due to the deformation vibration of $-\mathrm{CH}_{2}$ and $-\mathrm{CH}_{3}$, respectively. There was a good linear relationship for the methylene/methyl of paraffin with the ratio of $S_{1460}$ (peak area)/ $A_{1378}$ (absorbance). The reduction in the methylene/methyl ratio showed that the isomerization degree of paraffin products decreased as the final temperature of forced separation increased..$^{17-20}$ The absorption peak at $722 \mathrm{~cm}^{-1}$ was attributed to the in-plane oscillation of long-chain methylene. The intensity of the peak, which increased with the final temperature of the forced separation, was proportional to the length of the paraffin- $\left(\mathrm{CH}_{2}\right)_{n}$ - chain and was a quantitative index of the longchain paraffin content.

3.1.3.2 Analysis of the carbon atom distribution. The carbon atom distribution of normal paraffin determined the quality of PCMs. ${ }^{21,22}$ As shown in Fig. 4, there was no significant change in the carbon atom distribution, most of which was concentrated between $\mathrm{C}_{32}$ and $\mathrm{C}_{33}$ in raw paraffin and the fractions from the

Table 5 Grading the pre-set sweating temperature in the forced sweating process

\begin{tabular}{|c|c|c|c|c|c|c|}
\hline & Initial temperature & Sample A & Sample B & Sample C & Sample D & Sample E \\
\hline Temperature $/{ }^{\circ} \mathrm{C}$ & 58.0 & $<62.0$ & $62.0-64.9$ & $64.9-68.1$ & $68.1-69.5$ & $>69.5$ \\
\hline
\end{tabular}


Table 6 Properties of the forced separation products at different temperatures

\begin{tabular}{lcccccc}
\hline & Paraffin & Sample A & Sample B & Sample C & Sample D & Sample E \\
\hline Yield/\% & 98.4 & 36.5 & 24.3 & 10.7 & 10.8 & 16.1 \\
Melting point $/{ }^{\circ} \mathrm{C}$ & 64.3 & 60.0 & 64.0 & 66.4 & 67.6 & 0.11 \\
Oil content $/ \%$ & 0.46 & 0.55 & 0.24 & 0.17 & 0.07
\end{tabular}

forced separation of the paraffin products. However, compared with the raw paraffin wax, there was a significant change in the final fraction of sample $\mathrm{E}$, with the total content of the $\mathrm{C}_{32}$ and $\mathrm{C}_{33}$ components increasing by $6 \%$ from $23.19 \%$ to $29.32 \%$, which indicated that the carbon atom number distribution was drastically narrowed. Moreover, the content of $n$-paraffin increased by $22.06 \%$ from $67.75 \%$ in raw paraffin to $89.81 \%$ in the final fraction of sample E. Therefore, increasing the forced separation final temperature narrowed the range of carbon atom number distribution, increased the content of $n$-paraffin, and reduced the content of iso-paraffin, which indicated that forced sweating separation was an effective method for the preparation of paraffin with a melting point of $70{ }^{\circ} \mathrm{C}$.

3.1.3.3 DSC analysis of the products. As shown in Fig. 5, there are two peaks in the DSC data, the first one is for the solid-solid transition peak, and the second one is for the solid-liquid transition peak. The peak of the solid-solid transition peak, which is closely related to the composition of paraffin wax, became stronger gradually with the increase in $n$-paraffin content in paraffin wax and the narrowing of the carbon distribution. $^{23}$

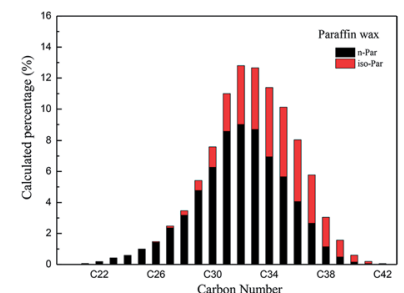

(A)

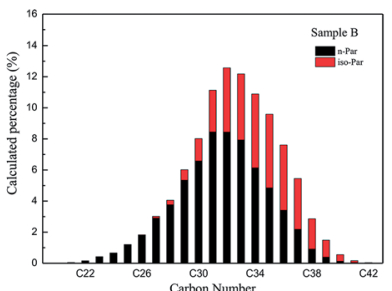

(C)

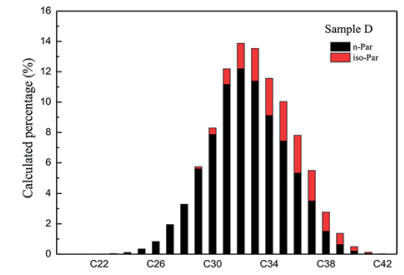

(E)

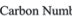

(F)

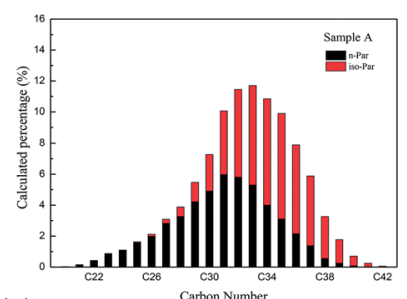

(B)

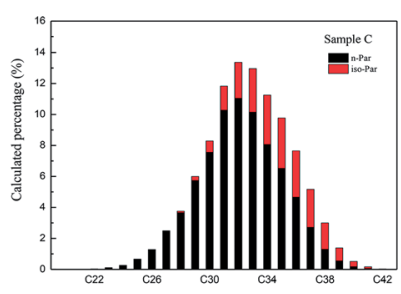

(D)

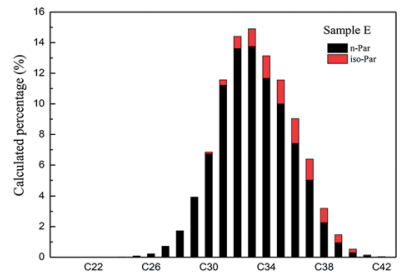

Fig. 4 Carbon atom distribution of the components through the forced separation.

Table 7 shows that the peak temperature of each fraction obtained through the forced separation of paraffin increased from $60.0{ }^{\circ} \mathrm{C}$ to $69.3{ }^{\circ} \mathrm{C}$, consequently, the latent heat increased from $155.44 \mathrm{~J} \mathrm{~g}^{-1}$ to $214.71 \mathrm{~J} \mathrm{~g}^{-1}$ compared with $186.05 \mathrm{~J} \mathrm{~g}^{-1}$ for the raw paraffin, whereas the temperature difference $T_{\text {-width }}$ decreased dramatically from $21.84{ }^{\circ} \mathrm{C}$ to $5.88^{\circ} \mathrm{C}$ compared with $11.38{ }^{\circ} \mathrm{C}$ of the raw paraffin. This indicated that high enthalpy paraffin with a melting point of $70{ }^{\circ} \mathrm{C}$ could be obtained through forced sweating separation. The final fraction obtained through the forced separation of paraffin exhibited better performance as a PCM than the raw paraffin, with a peak temperature of $69.74{ }^{\circ} \mathrm{C}$, latent heat of $214.71 \mathrm{~J} \mathrm{~g}^{-1}$, and $T_{\text {-width }}$ of $5.88{ }^{\circ} \mathrm{C}$, which was improved by $5.88{ }^{\circ} \mathrm{C}$ of the peak temperature, increased by $15.4 \%$ of the latent heat, and nar-

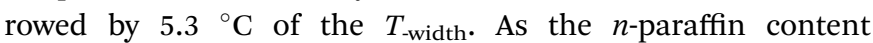
increased, a significant peak as a well-defined transition point for the solid-solid phase transition was displayed at a temperature of $57.6{ }^{\circ} \mathrm{C}$ in the fraction obtained through the forced separation.

3.1.3.4 XRD analysis of the products. It could be seen in Fig. 6 that there was no significant difference in the crystals structure for commercial paraffin wax and their narrow fractions obtained by vacuum sweating. Strong diffraction peaks near $21^{\circ}$ and $23^{\circ}$ in the XRD spectra indicated that the crystallization of

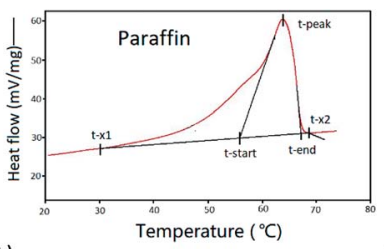

(A)

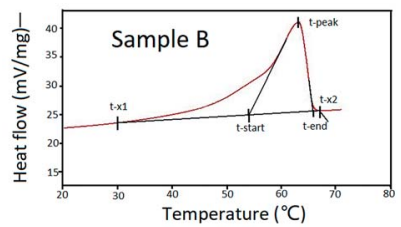

(C)

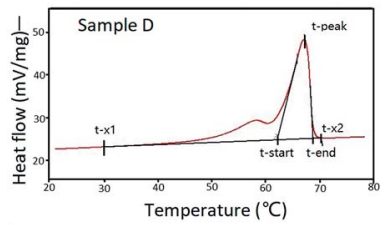

(E)

Fig. 5 DSC thermograms of the fractions obtained through the forced separation. 
Table 7 DSC results of the fractions from the forced separation of the paraffin products ${ }^{a}$

\begin{tabular}{|c|c|c|c|c|c|c|}
\hline & Paraffin & Sample A & Sample B & Sample C & Sample D & Sample E \\
\hline Yield, \% & 98.4 & 36.5 & 24.3 & 10.7 & 10.8 & 16.1 \\
\hline Melting point, ${ }^{\circ} \mathrm{C}$ & 64.30 & 60.0 & 64.0 & 66.4 & 67.6 & 69.3 \\
\hline$T_{\text {-start }},{ }^{\circ} \mathrm{C}$ & 55.88 & 41.06 & 54.47 & 59.58 & 62.19 & 65.01 \\
\hline$T_{\text {-peak }},{ }^{\circ} \mathrm{C}$ & 63.86 & 55.95 & 63.15 & 65.60 & 67.17 & 69.74 \\
\hline$T_{\text {-end }},{ }^{\circ} \mathrm{C}$ & 67.26 & 62.90 & 65.73 & 67.86 & 68.77 & 70.89 \\
\hline$T_{\text {-width }},{ }^{\circ} \mathrm{C}$ & 11.38 & 21.84 & 11.26 & 8.28 & 6.58 & 5.88 \\
\hline$\Delta H, \mathrm{~J} \mathrm{~g}^{-1}$ & 186.05 & 155.44 & 181.26 & 197.17 & 209.28 & 214.71 \\
\hline
\end{tabular}

${ }^{a} T_{\text {-start }}, T_{\text {-peak }}$, and $T_{\text {-end }}$ are the start, peak, and end of the solid-liquid transition temperatures, respectively. $T_{\text {-width }}$ is the difference between $T_{\text {-start }}$ and $T_{\text {-end; }} \Delta H$ is the energy of solid-liquid transition.

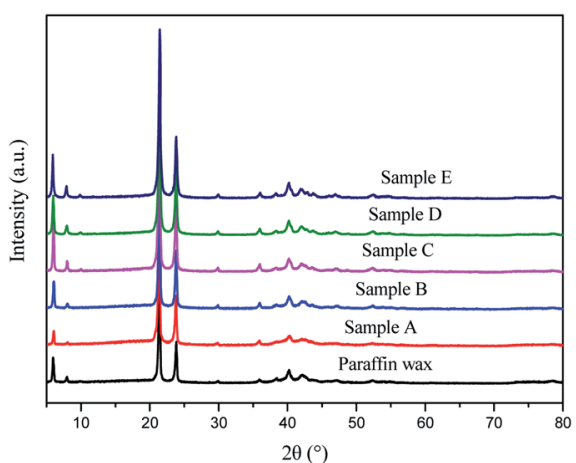

Fig. 6 XRD curve of the components obtained through the forced separation of paraffin.

paraffin wax followed an orthogonal structure, ${ }^{24-26}$ which was attributed to the XRD pattern of the $(110+111)$ and $(020)$ crystal faces, respectively. ${ }^{27}$ The presence of peaks for the commercial paraffin wax and the narrow fractions obtained by vacuum sweating at $21.4^{\circ}$ and $23.8^{\circ}$ coincided with the general characteristics of orthogonal crystals, which implied that the crystallization of paraffin and its separation fractions followed an orthogonal orientation.

3.1.4 Application of the forced separation products. The key index of the thermostat based on paraffin wax was the stroke and temperature control range on the thermal expansion associated with the solid-to-liquid phase transition of paraffin. Therefore, the performance of the wax thermostat was largely dependent on the property of the paraffin itself. The paraffin and its final fraction obtained through the forced separation,
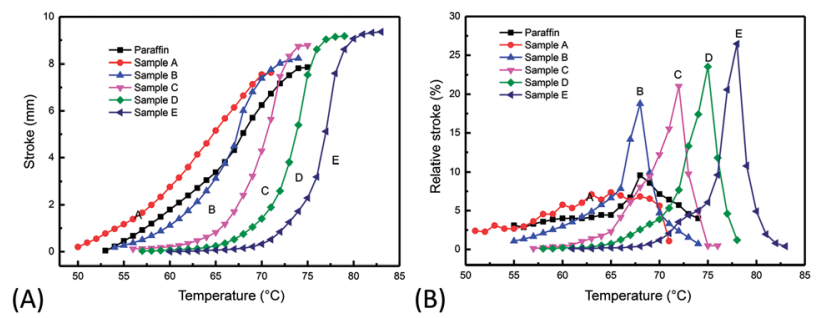

Fig. 7 Comparisons of the stroke and relative stroke with temperature increasing between paraffin and its final fraction obtained through forced separation for use as a thermostat. which was used as the paraffin phase change thermostat, was evaluated and the results are shown in Fig. 7.

As shown in Fig. 7A, the transport paths of the final fraction sample $\mathrm{E}$ was $8.75 \mathrm{~mm}$ in the temperature range $70^{\circ} \mathrm{C}$ to $80^{\circ} \mathrm{C}$; meanwhile the stroke was only $0.84 \mathrm{~mm}$ at $72^{\circ} \mathrm{C}$, which thus could be used for paraffin actuation. However, the transport path of the commercial paraffin (melting point of $64{ }^{\circ} \mathrm{C}$ ), manufactured by PetroChina Fushun Petrochemical Company, was less than $8 \mathrm{~mm}$ even in the temperature range from $54{ }^{\circ} \mathrm{C}$ to $74{ }^{\circ} \mathrm{C}$, which would not satisfy the engineering specification for an auto engine wax thermostat. This could be explained by the fact that commercial paraffin contains a small amount of oil, iso-paraffin, and small molecule $n$ alkanes, which easily result in shorter transport paths and a wider temperature range. As shown in Fig. $7 \mathrm{~B}$, the maximum relative stroke $(\max \Delta L \%)$ of the final fraction sample E was $26.5 \%$ (at $78{ }^{\circ} \mathrm{C}$ ), compared with $9.6 \%$ (at $68{ }^{\circ} \mathrm{C}$ ) for commercial paraffin. The temperature difference between the temperate of the maximum relative stroke and the temperature of the melting point was significantly increased to $8.7^{\circ} \mathrm{C}$, compared with the $4.1^{\circ} \mathrm{C}$ of commercial paraffin wax. Therefore, forced separation based on vacuum sweating could narrow the carbon atom distribution, improve the driving force, and increase the separation effect.

\section{Conclusions}

(1) An improvement in conventional sweating was systematically studied to overcome the difficulty encountered in completely separating the solid components and liquid components in paraffin with a high melting point. Vacuum operation was performed to increase the driving force of the separation, to improve mass transfer of the sweating process, to increase product yield, and to shorten the production cycle.

(2) Compared with the conventional sweating method, the yield of the product through vacuum sweating at $80 \mathrm{KP}$ increased by $12.7 \%$ from $39.9 \%$ to $52.6 \%$ at the same production specification of $2.75 \%$ oil content for the slack wax from Daqing crude oil.

(3) The separation efficiency for the final fraction of forced separation products was improved by $84.78 \%$ with an oil content of $0.07 \%$ through the vacuum sweating method without 
any chemical reaction, which could produce phase-change paraffin with a melting point of $70{ }^{\circ} \mathrm{C}$.

(4) Forced separation through sweating drastically increased the content of normal paraffin and narrowed the distribution range of the carbon atom number distribution. The latent heat of the phase changes was considerably improved, and the temperature difference between the start and end of the phase changes was reduced in the final fraction obtained through the forced separation of paraffin, which showed better performance than commercial paraffin when used as a PCM.

\section{Conflicts of interest}

There are no conflicts to declare.

\section{Acknowledgements}

The authors also acknowledge the financial supports from the PetroChina Fushun Petrochemical Company.

\section{Notes and references}

1 B. Zalba, J. M. Marın, L. F. Cabeza and H. Mehling, Appl. Therm. Eng., 2003, 23, 251-283.

2 N. Yuksel, B. Arabacigıl and A. Avcı, J. Renewable Sustainable Energy, 2012, 4, 063126.

3 A. Reyes, L. Henríquez-Vargas, R. Aravena and F. Sepúlveda, Energy Convers. Manage., 2015, 105, 189-196.

4 X. Qiu, L. Lu, P. Han, G. Tang and G. Song, J. Therm. Anal. Calorim., 2016, 124, 1291-1299.

5 P. Principi and R. Fioretti, Energy Build., 2012, 51, 131-142. $6 \mathrm{~S} . \mathrm{Wu}, \mathrm{D}$. Huang, F.-B. Lin, H. Zhao and P. Wang, J. Therm. Anal. Calorim., 2011, 105, 171-186.

7 Y. Hu, X. Song, Q. Zheng, J. Wang and J. Pei, RSC Adv., 2019, 9, 9962-9967.

8 S. Seitz, M. Akashi and H. Ajiro, Colloid Polym. Sci., 2017, 295, 1541-1548.
9 X. Kong, X. Chong, K. Squire and A. X. Wang, Sens. Actuators, $B, 2018,259,587-595$.

10 S. Seitz and H. Ajiro, Sol. Energy Mater. Sol. Cells, 2019, 190, 57-64.

11 S. Miller, Microporous Mater., 1994, 2, 439-449.

12 I. Kalambet and V. Dorodnova, Chem. Technol. Fuels Oils, 1982, 18, 331-333.

13 D. Bethge, Vac. Technol. Chem. Ind., 2014, 281-294.

14 F. Yan and Y. Cai, Pet. Sci. Technol., 2009, 27, 882-894.

15 J. R. Bowman and H. S. Burk, Ind. Eng. Chem., 1949, 41, 2008-2012.

16 R. Edwards, Ind. Eng. Chem., 1957, 49, 750-757.

17 S. Kumar, S. Nautiyal, H. Khan, K. Agrawal and J. Dimri, Pet. Sci. Technol., 2005, 23, 939-951.

18 a. R. M. Roehner and F. V. Hanson, Energy Fuels, 2001, 15, 756-763.

19 Q. Fan, G. Bai, S. Wu, W. Yuan and X.-M. Song, Pet. Sci. Technol., 2017, 35, 1495-1501.

20 Q. Fan, G. Bai, Q. Liu, Y. Sun, W. Yuan, S. Wu, X.-M. Song and D.-Z. Zhao, Ultrason. Sonochem., 2019, 50, 354-362.

21 C. Bai and J. Zhang, Ind. Eng. Chem. Res., 2013, 52, 27322739.

22 C. Nie, X. Tong, S. Wu, S. Gong and D. Peng, RSC Adv., 2015, 5, 92812-92817.

23 S. Srivastava, R. Tandon, D. Pandey, D. Madhwal and S. Goyal, Fuel, 1993, 72, 1345-1349.

24 S. Nautiyal, S. Kumar and S. Srivastava, Pet. Sci. Technol., 2008, 26, 1339-1346.

25 S. Pechook and B. Pokroy, Adv. Funct. Mater., 2012, 22, 745750.

26 Q. Tang, J. Sun, S. Yu and G. Wang, RSC Adv., 2014, 4, 3658436590.

27 C. Vélez, J. M. O. de Zárate and M. Khayet, Int. J. Therm. Sci., 2015, 94, 139-146. 